\title{
Seismic Optimization of Concrete Gravity Dams Using a Rubber Damper
}

\author{
Majid Pasbani Khiavi, Mortaza Ali Ghorbani and Arash Ghaed Rahmati \\ Faculty of Engineering, Department of Civil Engineering, University of Mohaghegh Ardabili, Ardabil, Iran.
}

(Received 13 November 2019; accepted 1 April 2020)

One of the major factors in an economic project of new concrete dams and safety valuation of available dams in seismic areas is the control and dissipation of the induced hydrodynamic pressure induced by dam and reservoir interaction. As one of the main control functions, dissipating the induced hydrodynamic pressure on the upstream face of the dam is considered in the evaluations. In this paper, the effects of a rubber damper as an isolation layer on the dam's seismic control have been investigated. For optimization of the rubber damper thickness and height, the Monte Carlo probabilistic analysis is used. The ANSYS program on the basis of finite element technique is applied for modeling and analysis. The Pine Flat dam in California, due to components of El Centro, San Fernando and North Ridge earthquake is modeled as a case study to evaluate the effect of upstream isolation layer on seismic control and optimization. The effect of the thickness and height of the rubber damper on reducing the responses is investigated and the optimum thickness and height are selected using sensitivity analysis for safe and economic design. The obtained results show the capability of the rubber damper in the seismic and hydrodynamic control of the sample model.

\section{INTRODUCTION}

The analyzing of concrete dams due to the presence of interaction effects is a very complex problem. Besides the static pressure of water, the dam is subject to dynamic forces of the reservoir when earthquake ground motion affects the system. In an earthquake, the dam body connected to the ground starts to fluctuate, while the water behind the dam is not directly affected by the seismic motion of the ground because of the low shear resistance of the water. So, the hydrodynamic pressure is only created by dam vibrations in the reservoir which spreads away to the reservoir upstream. Because of the interaction, the interface between the dam and the reservoir is a main boundary where the hydrodynamic forces are applied on the structure of the dam. These forces cause a considerable contribution to evaluate the seismic performance and design of the dam. ${ }^{1-3}$ During an earthquake, there is a significant relationship between the hydrodynamic pressure and the seismic response of a concrete gravity dam. The resulting stresses may cause a to crack to occur with propagation in the dam over relatively severe seismic phenomena. The direct approach to reduce the response of a concrete dam is to increase its structural damping to a desired high value. However, due to the nature of the dam structure and the concrete material properties, no significant action can be done for the structural damping aspect of response reduction. ${ }^{4}$ Bayraktar et al. investigated the effect of reservoir length on seismic performance of gravity dams to near-and far-fault ground motions using the finite element method. 5 They considered the linear and nonlinear behavior for a concrete body. The obtained results illustrated that the length of reservoir affects the seismic responses, considerably. Also, the induced stress on the dam body is more due to near-fault ground motions in comparison with far-fault ground motions. Wang et al. investigated the effect of near fault and far-fault ground motion on seismic performance of the Koyna gravity dam using the concrete damaged plasticity model for nonlinear analysis. The obtained results showed the importance of the near-fault ground excitations on seismic performance of the model. ${ }^{6}$

Recently, energy dissipation was used in the structures with application of seismic isolation and protection systems. ${ }^{4}$ These systems can reduce the seismic responses imposed on the structure during an earthquake. The performance of these systems presents a new design philosophy that focuses on increasing the capacity of energy dissipation in the structures. In other words, the earthquake energy, instead of absorbing and causing failures in structural elements, is absorbed in this system. As one of the modern technologies, the seismic isolation and control systems have been more used in the structural engineering such as structures, bridges and dams, the practical effects of which are proven in several strong earthquakes. It has become a new improved method for earthquake engineering.

Due to the nature of the dam structure and the concrete material properties, there is little that can be done on the structural damping aspect of response reduction. The idea of reducing the hydrodynamic loading on the dam appears to be a promising approach for seismic response reduction of concrete dams, though it is still in the early stages in the field of safety of large dams. The separation interface is placed on the upstream face of dams. One of the first ideas for reducing hydrodynamic pressure on the dam by an air curtain at the upstream side of the dam has been examined by Lombardo et al., Sheinin, and Savinov et al. ${ }^{7-9}$

As'kov et al. ${ }^{10}$ and Gellis et al. ${ }^{11}$ examined the idea of hydrodynamic isolation by laboratory model tests as well as measurements of the dam prototypes equipped with an air curtain.

In recent researches, Zhang et al. using the finite element model, studied air cushion impact to reduce the Jinping dam seismic responses with $305 \mathrm{~m}$ height. ${ }^{10}$ They used the Eulerian-Lagrangian formulation for modeling and analysis. Their obtained results illustrated that applying an air cushion in 
the dam upstream, reduced the hydrodynamic pressure applied to dam heel by 50 percent and also reduced principle stress by approximately 30 percent. Also, Mirzabozorg et al. investigated the effect of air curtains on reducing the hydrodynamic pressure on the Amirkabir arch dam. ${ }^{11}$ They showed that air cushion separators reduce interaction effects between the dam and the reservoir in large amount. Chen et al. studied the isolation and anti-cracking effects of the air-cushion on seismic behavior of a high arch concrete dam. ${ }^{12}$ The obtained results show that the air-cushion decreases the cracking range of the dam body effectively and the isolation effects of the aircushion are considerable.

The restricted parameters of the use of the seismic aircushion to dams for the most part are several dependent structures and tools placed on the upstream face of dams and the remainder is reservoir sedimentation. These parameters will limit the range corresponding to the installation of the seismic air cushion. Therefore, to reduce the effect of the dam and reservoir interaction on seismic responses the using of hydrodynamic dampers on the upper face of the dam is a better option. The use of hydrodynamic dampers, in addition to reducing the hydrodynamic pressure applied on the dam body, is economically less costly than other designs. ${ }^{4}$ The effects of soft material that reduce the seismic response of the dam were investigated by Hall et al. ${ }^{15,16}$ They reported promising results in the reductions of the hydrodynamic force exerted on the dam due to the effect of the isolation layer. Hatami studied the reduction of hydrodynamic pressure using an isolation layer as an absorbing boundary at the contact site of the dam and reservoir using analytical solutions in the frequency domain. ${ }^{4}$ The researches show that there are few problems associated with the use of the isolation layer considering appurtenant structures and performance restrictions.

So, in this paper the possibility of reducing induced hydrodynamic pressure on the dam body by means of the rubber damper as an isolation layer under seismic loading is investigated in detail. To obtain the optimum thickness and height of the isolation layer, the Monte Carlo simulation with Latin Hypercube Sampling (LHS) is used. The thickness and height of the rubber damper are assumed as random input variables. During the earthquake, the highest amount of horizontal movement of the dam crest, maximum hydrodynamic pressure, 1 st principle tensile stress of the heel and $3^{\text {rd }}$ principle compressive stress of the dam toe are considered as critical responses in the probabilistic model analysis.

\section{RUBBER DAMPER ISOLATOR}

The interface of the dam with impounded water is an important boundary where the static and hydrodynamic forces are applied to the dam structure. These forces provide a significant contribution to the seismic response analysis and design of the dam. The maximum hydrodynamic pressure on the dam when subjected to a moderately strong earthquake ground motion may reach the magnitude of the hydrostatic pressure. The isolation layer can have a reducing effect on responses of the dam model because of damping the induced hydrodynamic pressure on the upstream face of the dam due to an earthquake.

The good performance of a rubber damper is indicative of the significant effect of the water - structures' interaction on seismic responses against the dam. Therefore, in old or dam- aged structures, where the water-structure interaction is not considered in their design, the use of a rubber damper is very convenient.

The performance of the rubber damper as an isolation layer is not complex in terms of behavior and modeling. The governing equation of the rubber damper behavior is similar to the solid-part equation of the dam-reservoir-foundation system. However, due to the low modulus of elasticity for a rubber damper, stiffness is low and flexibility is high. High flexibility ensures that when the hydrodynamic pressure waves collide with the isolation layer, most of the pressure is absorbed partially and depreciated inside the rubber damper. As a result, little amount of hydrodynamic pressure enters the dam body or reflected to the reservoir. ${ }^{4}$ This mechanism will result in the system withstanding less hydrodynamic force because of dam-reservoir interaction during an earthquake.

\section{MONTE CARLO PROBABILISTIC ANALYSIS}

Static and dynamic analysis of structures is usually done by assuming a certain amount of parameters will influence the structural seismic responses. Although, assuming the certainty of the model leads to faster and simpler analysis, structural analysis should be conducted in an uncertainty analysis despite the uncertainty in loading, geometric and material properties. Many researchers have been focused on the study of structures by considering the uncertainty characteristics of materials, geometry and so on. Recently, the probabilistic simulation methods are used in different sciences. Understanding the strengths and weaknesses of this efficient tool will create new possibilities for researchers. Among the various methods of probabilistic simulation, the Monte Carlo method is a more suitable tool for the research than other methods. This method has been used for seismic analysis of concrete dams in the recent years.

Since the design parameters of the dams cannot be calculated accurately and there is uncertainty in the calculations, calcualting the stability of the dams will be also uncertain. The LHS simulation is one of the most widely used and accurate methods of structural reliability analysis. In this method, different design parameters, which cannot be calculated accurately, can be considered as a probability distribution function.

Fairbairn et al. studied the probability of crack expansion in a concrete gravity dam by using the LHS simulation. ${ }^{17}$ In their study, the results obtained from the LHS simulation were compared to the results of testing a laboratory model indicating a good match between the simulation results and the laboratory results. Kostov et al. evaluated the reliability of a dam using a finite element software called NISA which was capable of simulating the LHS method. ${ }^{18}$ The results of this simulation are presented as cumulative distribution graphs. Yanmaz and Beşer performed the reliability analysis of the Pursuk dam in Turkey through the LHS simulation. ${ }^{19}$ In their study, they defined seven parameters as variable and provided the results in a table indicating the probability of failure based on dam safety factors. Rohaninejad and Zarghami presented a new method which was a new combination of Monte Carlo simulation and finite element method. ${ }^{20}$ In their study, they evaluated the dam behavior and showed the simulation results as a cumulative distribution function curve. Lupoi and Callari proposed the probabilistic procedure applying Monte Carlo simulation 
which is able to account for uncertainties in material properties and an external condition such as ground motion and reservoir heights with computation of fragility curves. ${ }^{21}$ Minor differences were observed in obtained results considering uncertainties in material behavior assuming three levels in the reservoir. An applied probabilistic model in their research was able to estimate the corresponding reduction in the probability of failure. Altarejos et al. studied the reliability of a concrete gravity dam against sliding using Monte Carlo simulation. ${ }^{22}$ They considered ten variable parameters in their study and showed the results as a failure probability curve against sliding for each variable.

Feng et al. attempted to analyze the reliability of hydraulic structures by combining MATLAB with Monte Carlo method for the reliability of large hydraulic structures. ${ }^{23}$ The results of their study revealed that the methods based on MATLABMonte Carlo model are reliable and fast in the reliability of hydraulic structures and have a good function. Mirzabozorg et al. used the Monte Carlo method to create three-dimensional non-uniform ground motions for comparing the effect of threedimensional uniform and non-uniform ground motions on the response of the Dez arch dam. ${ }^{24}$ The results of their study indicated that the responses obtained from considering threedimensional non-uniform ground motions are different from uniform ground motions and can enhance the structural responses of the system. Alembagheri and Seyedkazemi used Monte Carlo probabilistic analysis and the LHS method to show that the modulus of elasticity and tensile strength of concrete play a more significant role than its final strain against the earthquake. ${ }^{25}$ Pasbani Khiavi studied the sensitivity of seismic responses of a concrete gravity dam to the reservoir bottom absorption using Monte Carlo probability analysis and the LHS method. ${ }^{26}$ The results of this study indicated the effect of a reservoir bottom on the seismic performance of the dam. Chiti et al. used the subset simulation with Markov Chain and the LHS as an advanced reliability analysis tool to evaluate the probability of dam failure with the lowest number of samples. $^{27}$

Also, Pasbani Khiavi simulated the influence of the concrete stiffness on the seismic performance of concrete gravity dams. $^{28}$ The Monte Carlo simulation was used in the analysis. According to the results, the optimized value of the concrete Young modulus can be achieved to access the confident response of the structure with considering economic aspects. Sevieri et al. presented a new hybrid-predictive model using the probabilistic method based on the Bayesian framework for parametric evaluation of finite elements models of concrete gravity dams. ${ }^{29}$ The computational effort is reduced by using the proposed model of the dam displacements. The proposed probabilistic model consists of a set of functions that correct the model bias with calibration of the unknown parameters and is able to control the structural performance after an earthquake.

Currently, the reliability analysis methods are mainly used based on the probability theory in which the random parameters are assumed to follow a certain specified distribution. The reliability indexes are varied according to different distribution forms and a certain selected distribution form cannot be applied in all conditions. Moreover, the probabilistic reliability analysis model is highly sensitive to the values of parameters. ${ }^{30}$

The theory of probabilities is a mathematical framework for quantifying the uncertainties in decision making. Almost all of the parameters needed to design a structure, such as mass, damping, material properties, boundary conditions and ground motion are uncertain. These uncertainties should be identified to design a safe structure. The concept of a safe structure refers to the structures that continue to function without damage for many years and the builder is responsible for constructing the structures in such a way that failure does not occur in them. ${ }^{31}$

\subsection{Basic Concept}

There are several methods for solving the problems related to structural reliability. Simulation methods are a possible method of solving such problems. The concept of simulation is quite clear while the process can be very difficult. The Monte Carlo method is a special technique which can be used for generating some numerical results without any physical test. ${ }^{32,33}$ In this method, the results obtained from previous tests can be used for creating probabilistic distributions from important parameters in problems. Then, this distribution of information can be used for generating some samples of data. The Monte Carlo method along with LHS is often used in three cases:

- In solving complicated problems which are solved with difficulty or are impossible to be solved. For example, it can be used in solving probabilistic problems including complicated nonlinear finite element models with high computational effort;

- it can be used in solving the problems which can be solved approximately by consideing simplifying assumptions. In fact, such problems can be studied without performing such simplifications through the Monte Carlo simulations and the results are closer to the real results; and,

- this method can be used for evalauting the results of other solving methods.

\subsection{Latin Hypercube Sampling Method}

The Monte Carlo sampling and simulation method is a very useful and powerful method. However, sometimes the analysis problem is very complicated and may take a long time to complete the analysis. As a result, the required time for hundreds or thousands of simulations may be impossible. LHS is a technique for reducing the number of required simulations to obtain acceptable results. In this method, a range of possible values of random input variables is partitioned inside some layers and a value of each layer is selected randomly as the representative value. These representative values which represent each random variable are combined together in such a way that each representative value is considered only once in the process of simulation. In this method, all possible values of random variables are presented in the simulation. Consider the limit state function $Y$ with the following random variable $K:^{33}$

$$
Y=f\left(X_{1} \cdots X_{k}\right)
$$

The basic steps of the LHS technique are as follows:

- Each $X_{i}$ is partitioned at certain intervals ( $N$ intervals). This partitioning should be in such a way that the probability of the occurrence of any value of $X_{i}$ at these intervals is equal to $1 / N$. 
- For each variable $X_{i}$, each of its $N$ interval is selected randomly as a representative value. In practical applications, if the number of intervals is too high or large intervals are selected, the central point of each interval will be selected instead of random sampling.

- After the above steps, the representative value $N$ is obtained for each random variable $K$. In general, there may be $N^{K}$ possible combinations of these values.

The objective of the Latin hypercube sampling method is to select $N$ combinations, so that each representative value appears only once in $N$ combinations.

In order to obtain the first combination, one of the representative values for each random input variables $K$ is selected randomly. For obtaining the second combination, one of the $N-1$ remaining representative value of each random variable is randomly selected. In order to obtain the third combination, one of the $N-2$ remaining representative values of each random variable is selected randomly. This selection process continues until $\mathrm{N}$ combinations are composed of the values of input variables. ${ }^{33}$

Eq. (1) is evaluated for each $N$ combination of the abovementioned input variables. Thus, the $N$ functions of $Y_{i},(i=$ $1,2, \cdots, N)$ will be obtained.

This process creates simulation data; and using data should be determined for estimating statistical parameters for $y$. The most common formulas include:

$$
\begin{gathered}
\tilde{Y}=\frac{1}{N} \sum_{i=1}^{N} y_{i} ; \\
Y=\frac{1}{N} \sum_{i=1}^{N}\left(y_{i}\right)^{m} ; \\
F_{y}(y)=\frac{\text { number of times } y_{i} \leq y}{N} .
\end{gathered}
$$

The basis for all LHS simulation steps is generating random numbers being uniformly distributed between 0 and 1 . When there is an understanding that $U$ is related to the uniform distribution of random number $U$ between 0 and 1 , it is possible to produce $x$ related to the uniform distribution of random number $X$ between both values $a$ and $b(a \leq x \leq b)$ using the following equation: ${ }^{33}$

$$
x=a+(b-a) \cdot U .
$$

In addition, the generated sample values $i$ derived from the uniform random distribution between two integers $a$ and $b$ were considered through the following equation:

$$
i=a+\operatorname{TRUNC}[(b-a+1) \cdot U]
$$

where $T R U N C$ refers to the function which eliminates the decimal part of the variable.

In the present study, the correlated variables are analyzed and it is explained how the simulation process creates such a correlation. A conversion method for simulating the correlated normal random variables is indicated below. Although it is valid only for normal random variables, it can be also used approximately for other types of random variables.
Table 1. Material properties of a system.

\begin{tabular}{|c|c|c|c|c|c|}
\hline \multirow{2}{*}{ Parameters } & \multirow{2}{*}{ Symbol } & \multirow{2}{*}{ Dimension } & \multicolumn{3}{|c|}{ Value } \\
\cline { 4 - 6 } & & & Dam & Foundation & $\begin{array}{c}\text { Rubber } \\
\text { damper }\end{array}$ \\
\hline Density & $\nu$ & $\mathrm{kg} / \mathrm{m}^{3}$ & 2483 & 0 & 1300 \\
\hline Poisson's ratio & $\rho$ & - & 0.2 & 0.33 & 0.499 \\
\hline Elasticity modulus & $E$ & $\mathrm{GPa}$ & 22.4 & 22.4 & 0.5 \\
\hline
\end{tabular}

\section{GOVERNING EQUATIONS OF THE SYSTEM}

The governing equation of the solid part of the system is the motion equation. ${ }^{1}$ In the fluid and solid interface the load of hydrodynamic pressure must be added to dynamic loads. Therefore, the system equation for dam, foundation and isolation layer body is presented as:

$$
M \ddot{u}+C \dot{u}+K u=M \ddot{u}_{g}+F^{P r} .
$$

In Eq. (7), $M$ refers to mass matrix, $C$ represents the damping matrix and $K$ is the structural stiffness matrix. $u$ represents the relative movement vector, $\ddot{u}_{g}$ refers to the ground acceleration vector. $F^{P r}$ is the vector of induced hydrodynamic pressure applied at the contact of water with solid parts.

Assuming that the water inside the reservoir is inviscid, compressible with small displacement, the combination of equations of continuity and momentum leads to the wave equation. So, the governing equation of reservoir is defined as: ${ }^{1}$

$$
\frac{1}{C^{2}} \frac{\delta^{2} p}{\delta t^{2}}-\nabla^{2} P=0
$$

where $c$ represents the velocity of sound in the fluid environment, $P$ refers to the hydrodynamic pressure and $t$ represents the time.

\section{CASE STUDY}

To show the efficiency of the analysis process offered in the current study and the effect of the isolation layer on seismic optimization of concrete gravity dams, the response of Pine flat dam under the both components of longitudinal and vertical of El Centro, San Fernando and North Ridge earthquakes is presented. The longitudinal and vertical components of selected earthquakes have been applied to dam-reservoir system in both horizontal and vertical directions. The Pine Flat dam geometry and finite element model related to dam-reservoirfoundation system with the isolation layer attached to upstream face is presented in Fig. 1. ${ }^{34}$ The characteristic of material parameters of the system have been shown in Table $1 .^{4,35}$ For the reservoir, density and bulk modulus corresponding to water are considered as $1000 \mathrm{~kg} / \mathrm{m}^{3}$ and $2.1 \mathrm{GPa}$.

\section{MODEL ANALYSIS}

In this research, the FE-ANSYS software is used for the analysis and seismic optimization of a concrete dam. This software has the ability to consider the irregular geometry domains and interaction effects for seismic analysis. Accordingly, suitable components have been provided for fluid compressibility behavior in FE-ANSYS. According to the geometry and behavior of a concrete gravity dam and reservoir, the dam is intended for two-dimensional plane stress behavior, and the effects of interactions with the foundation has been considered 


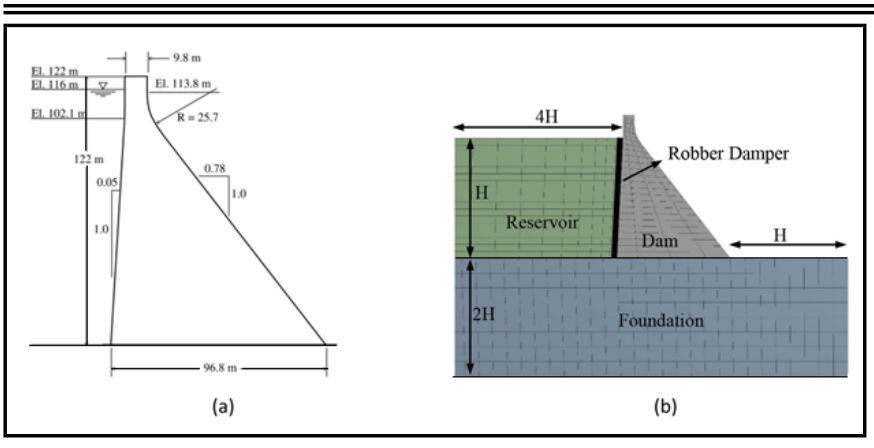

Figure 1. (a) Dimensions and geometrical cross-section of Pine Flat dam; (b) Model of the dam-reservoir-foundation isolation layer in ANSYS software.

Table 2. Characteristics of selected earthquakes.

\begin{tabular}{|c|c|c|}
\hline Earthquake name & Station name & RRUP $(\mathrm{km})$ \\
\hline Northridge-01 & Castaic-Old Ridge Route & 20.72 \\
\hline Imperial Valley-02 & El-Centro Array \#9 & 6.09 \\
\hline San Fernando & Pacoima Dam (upper left abut) & 1.81 \\
\hline
\end{tabular}

Table 3. Monte Carlo setting in FE-ANSYS software.

\begin{tabular}{|c|c|c|c|}
\hline Random input & Distribution type & $\begin{array}{c}\text { Number } \\
\text { of simulations }\end{array}$ & $\begin{array}{c}\text { Number } \\
\text { of repetitions }\end{array}$ \\
\hline Thickness & Uniform & 40 & 3 \\
\hline
\end{tabular}

in the model. An 8-node SOLID182 element has been selected for the discrete solid part, and 4-node FLUID29 element has been used in the reservoir domain. ${ }^{36}$ The output variables, including the dam displacement, induced stress of the dam body, and the hydrodynamic pressure generated in the reservoir, are extracted by analyzing the model. According to the UBC bylaws, horizontal and vertical components of earthquakes extracted from the peer site, shown in Table 2 are scaled to the maximum acceleration of the dam area $(0.3 \mathrm{~g})$. The amounts of integration factors of the Newmark technique are considered as $\beta=0.25$ and $\gamma=0.5 .^{37}$ Moreover, Sommerfeld indicated that the boundary condition is applied as a far field reservoir boundary. Using the first and second frequency of the system, Rayleigh damping coefficients are extracted as $\alpha_{1}=0.5202$ and $\alpha_{2}=0.0046$. The results of the Monte Carlo probability analysis should be a proper convergence. To achieve this goal, the Monte Carlo simulation setting in the FE-ANSYS software is intended in Table 3.

\subsection{Model Sensitivity to Discretization}

One of the most important modeling steps in finite element software is the discretization of the system. Discretization in the model must be converged so finer discretization does not affect the results considerably. Hence, in this paper, through Monte Carlo probability analysis and with APDL programming in ANSYS software, optimum discretization of the model was achieved with regard to investigation of the effect of discretization size on seismic responses of the concrete gravity dam.

The results which indicate the sensitivity of seismic responses of the dam to the size of the mesh in the model without the rubber damper under El Centro earthquake are extracted from probability analysis in ANSYS software. It is noteworthy to mention that the horizontal axis of the diagrams indicates the size of the mesh, wherein rise presents finer meshes. Figs. 2 show the sensitivity of the seismic responses of the model to the size of the mesh under the El Centro earthquake.
Table 4. Characteristics of uncertainty parameters of the model for the Monte Carlo probabilistic analysis settings.

\begin{tabular}{||c|c|c|c|c||}
\hline Input variable & $\begin{array}{c}\text { Number } \\
\text { of } \\
\text { repetitions }\end{array}$ & $\begin{array}{c}\text { Number } \\
\text { of } \\
\text { simulation loops }\end{array}$ & $\begin{array}{c}\text { Range } \\
\text { of } \\
\text { variation }\end{array}$ & $\begin{array}{c}\text { Type } \\
\text { of } \\
\text { distribution }\end{array}$ \\
\hline $\begin{array}{c}\text { Thickness } \\
\text { of rubber } \\
\text { damper }(\mathrm{cm})\end{array}$ & 3 & 40 & $0<X<60$ & uniform \\
\hline $\begin{array}{c}\text { Height of } \\
\text { of rubber } \\
\text { damper }(\mathrm{m})\end{array}$ & 3 & 40 & $0<X<120$ & uniform \\
\hline
\end{tabular}

\section{MODEL ANALYSIS}

According to the results, finer meshes affect the seismic responses of the dam until a limited value; beyond that more meshings do not affect the responses noticably. Therefore, through employing Monte Carlo probability analysis, it is possible to specify the optimum meshing for every earthquake.

\subsection{Model Sensitivity to Number of Samples}

In the Monte Carlo probabilistic analysis, histogram diagrams of output variables must be converged to the number of simulations. Hence probability analysis settings in ANSYS software are mentioned in Table 4.

After Monte Carlo probabilistic analysis of the dam model under El Centro earthquake, to verify the results, first, histogram diagrams of mean values of output variables with the number of samples are studied. If the number of simulation samples are enough, there is convergence for the mean value of output variables and the curves tend to be flat at their end. Figs. 3 illustrates the histogram curve of output parameters with the number of samples.

The horizontal end of the simulated histogram curves in Figs. 3 indicate the number of simulation samples are sufficient for the probabilistic Monte Carlo analysis.

\section{SENSITIVITY ANALYSIS OPTIMIZATION OF RUBBER DAMPER}

After the selection of optimum discretization and the number of samples for analysis of model in this section, the effect of thickness and height of a rubber damper on the seismic performance of the model under three selected scaled ground motions are investigated using probabilistic method. For sensitivity analysis, the dam crest displacement, maximum hydrodynamic pressure and principle stresses are selected as output parameters and the effect of thickness and height of the rubber damper on the seismic response of the model is evaluated.

\subsection{Optimization of the Rubber Damper Thickness}

Considering the thickness of the rubber damper as input of the parameters for sensitivity analysis and increasing the rubber damper performance reliability, the results of the model analysis under the El Centro, San Fernando and Northridge earthquakes are shown in Figs. 4 to 7

Fig. 4 shows that for the system under the El Centro earthquake, the rubber damper efficiently reduces the hydrodynamic pressure when the thickness of the rubber damper is smaller 


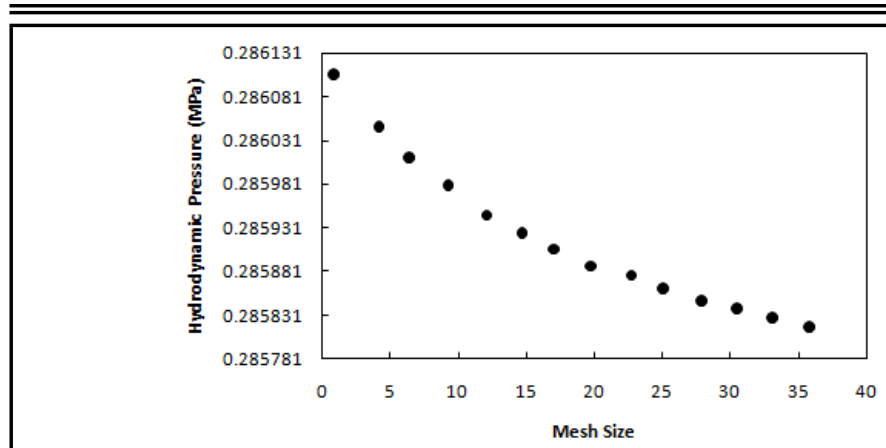

(a)

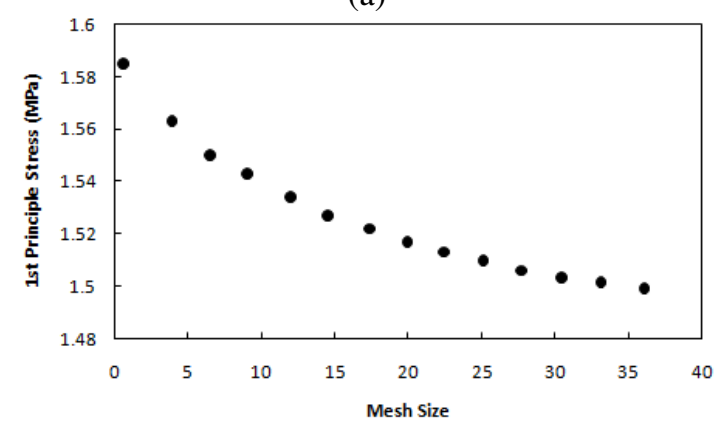

(c)

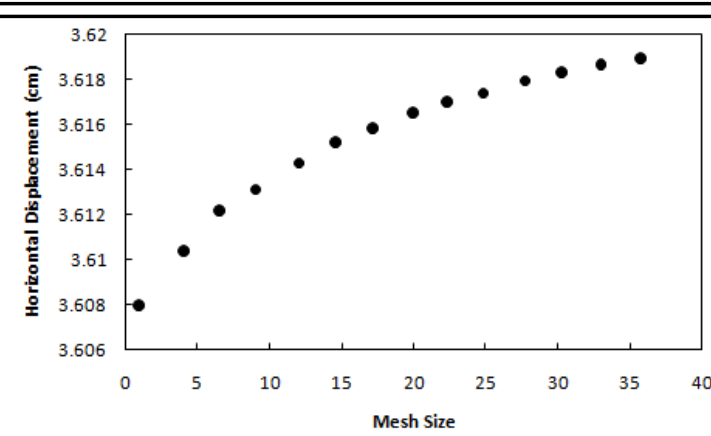

(b)

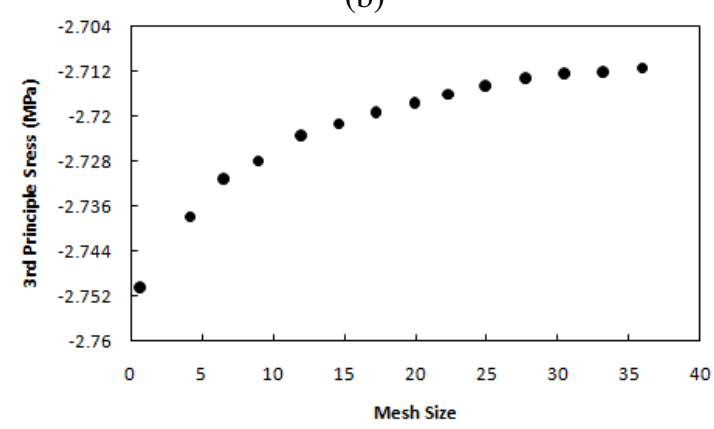

(d)

Figure 2. Sensitivity curve of critical responses to the mesh size: (a) Sensitivity of the hydrodynamic pressure (b) Sensitivity of horizontal displacent (c) Sensitivity of 1 st principle stress (d) Sensitivity of 3rd principle stress.

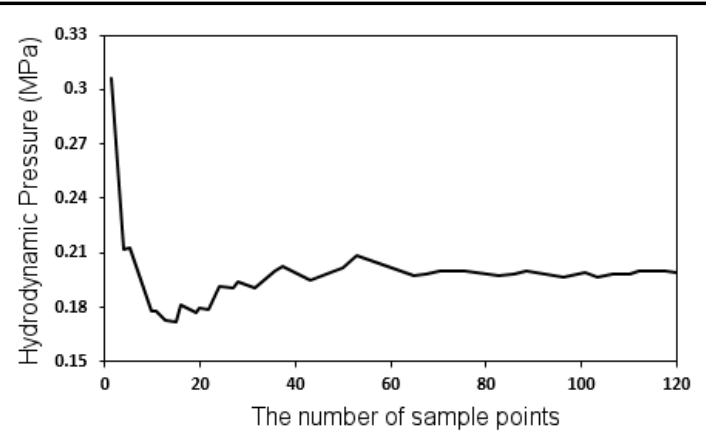

(a)

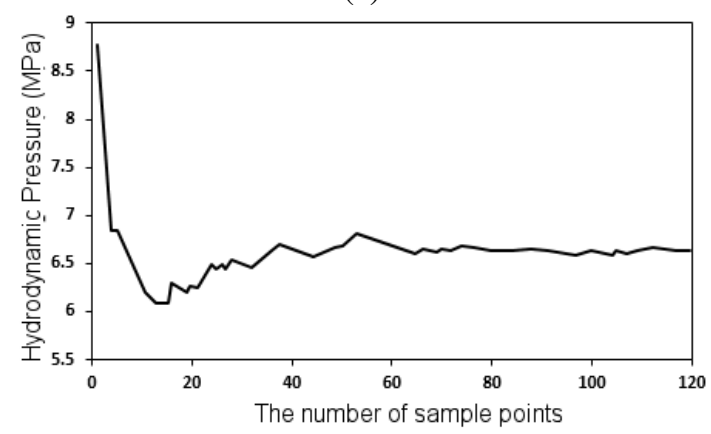

(c)

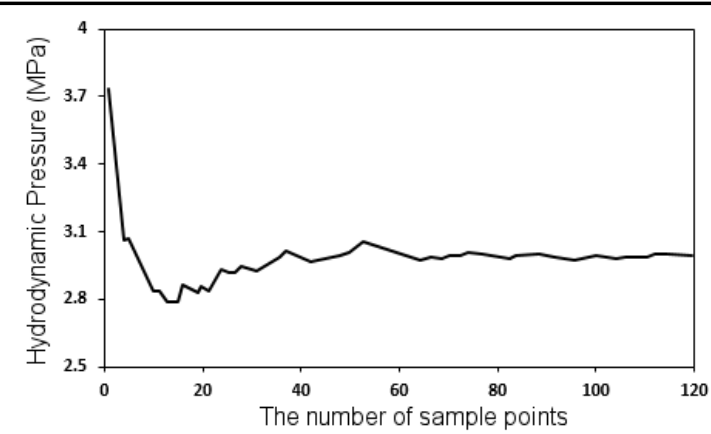

(b)

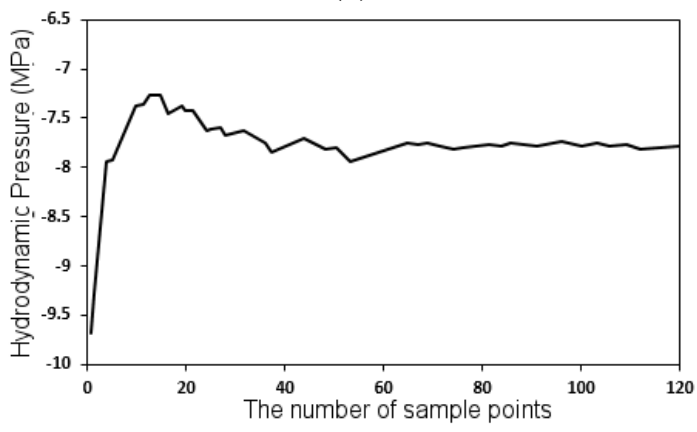

(d)

Figure 3. Histogram curve of critical responses with the number of samples: (a) Histogram curve of the hydrodynamic pressure; (b) histogram curve of horizontal displacement; (c) histogram curve of $1^{\text {st }}$ principle stress; (d) histogram curve of $3^{\text {rd }}$ principle stress.

than $30 \mathrm{~cm}$ and a further increase in thickness of the rubber damper has an insignificant effect on hydrodynamic pressure. The San Fernando earthquake represents a suitable performance of the isolation in the reduction of hydrodynamic pressure application on the dam's upstream face and is a layer with a thickness of $10 \mathrm{~cm}$. The hydrodynamic pressure acting on the dam is effectively reduced for a layer of $20 \mathrm{~cm}$ of the rubber damper under the Northridge earthquake.
Fig. 5 demonstrates the proper performance of the rubber damper in order to reduce the horizontal displacement of the dam crest with a thickness of less than $30 \mathrm{~cm}$ under the $\mathrm{El}$ Centro earthquake. For the San Fernando earthquake, the horizontal displacement of the dam crest is effectively reduced in thickness of less than $10 \mathrm{~cm}$ and the rubber damper shows a proper performance. In addition, it was found that the further increase in thickness does not have a significant effect in the 


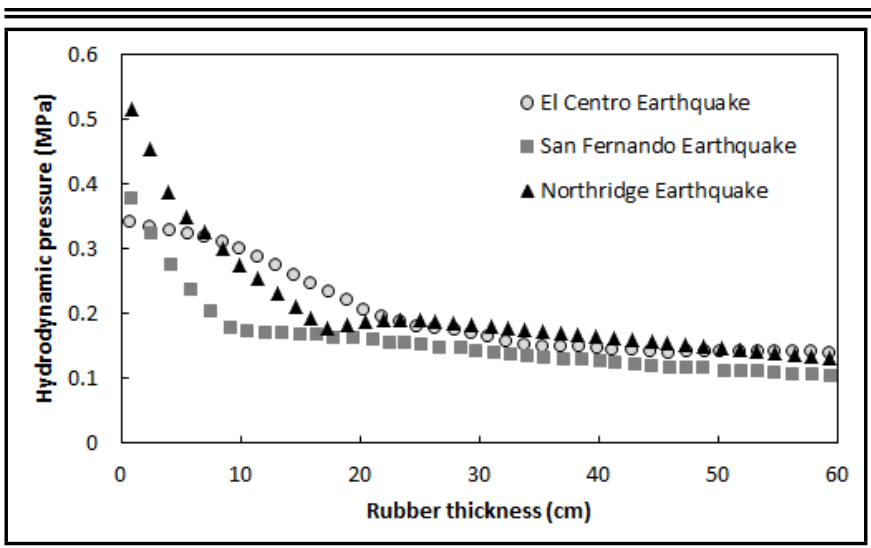

Figure 4. Sensitivity of the hydrodynamic pressure of the dam heel to the thickness of the rubber damper.

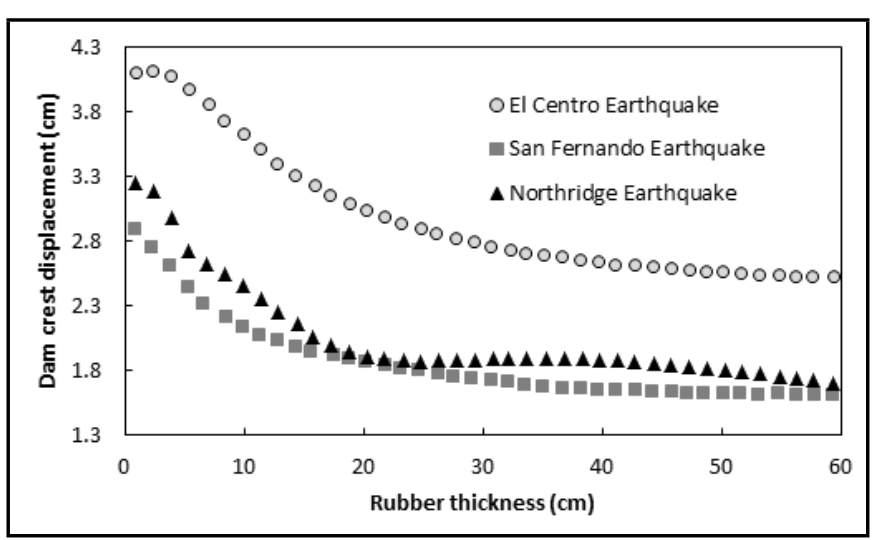

Figure 5. Sensitivity of the horizontal displacement of dam crest to the thickness of the rubber damper.

reduction of response. The horizontal displacement of the dam crest is significantly decreased as long as the thickness of the rubber damper is smaller than $20 \mathrm{~cm}$ due to the Northridge earthquake.

Fig. 6 illustrates that the rubber damper of a thickness of $20 \mathrm{~cm}$ has a proper performance in reducing the $1^{\text {st }}$ principle stress of dam heel under the El Centro earthquake. In this figure, the first principle stress of the dam heel, is decreased significantly while the rubber damper thickness is less than $20 \mathrm{~cm}$. This figure shows that increasing the thickness of the rubber damper by more than $20 \mathrm{~cm}$, does not demonstrate a significant effect on reducing the $1^{\text {st }}$ principle stress of the dam heel for the system due to the San Fernando earthquake. Also, it is obvious from this figure the $1^{\text {st }}$ principle stress of the dam heel is effectively reduced for the rubber damper with a thickness of $10 \mathrm{~cm}$ due to the Northridge earthquake. However, further increase in the thickness of the rubber damper does not have a significant effect in reducing response.

Fig. 7 shows that under the El Centro earthquake the third principle stress in the toe of the dam is decreased significantly in a thickness of $20 \mathrm{~cm}$ of the rubber damper. It is obvious from the figure that the third principle stress of the dam toe is effectively reduced to a thickness of $20 \mathrm{~cm}$ of the rubber damper due to the San Fernando earthquake. The reduction of the third principle stress in the toe of the dam is significant for the rubber damper with a $10 \mathrm{~cm}$ thickness under the Northridge earthquake.

Finally, for the proper evaluation of the isolation layer effect with different thicknesses on reducing seismic responses, the

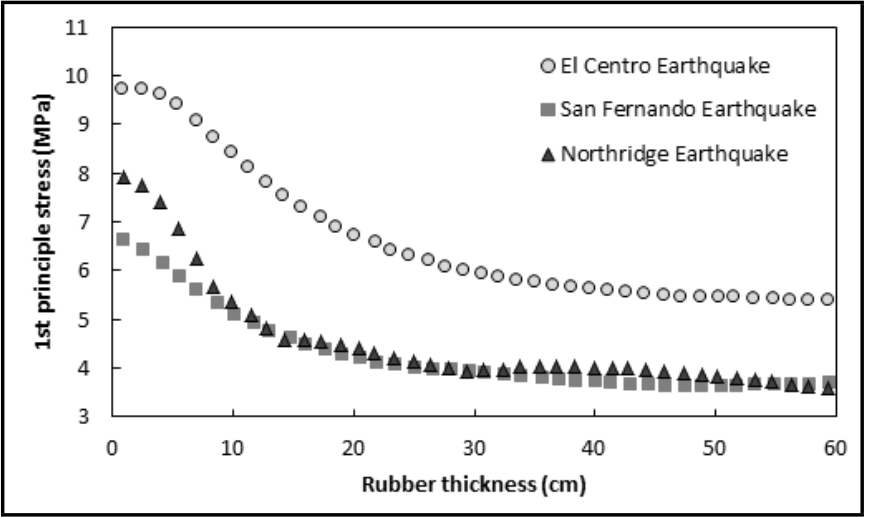

Figure 6. Sensitivity of the $1^{\text {st }}$ principle stress of the dam heel to the thickness of the rubber damper.

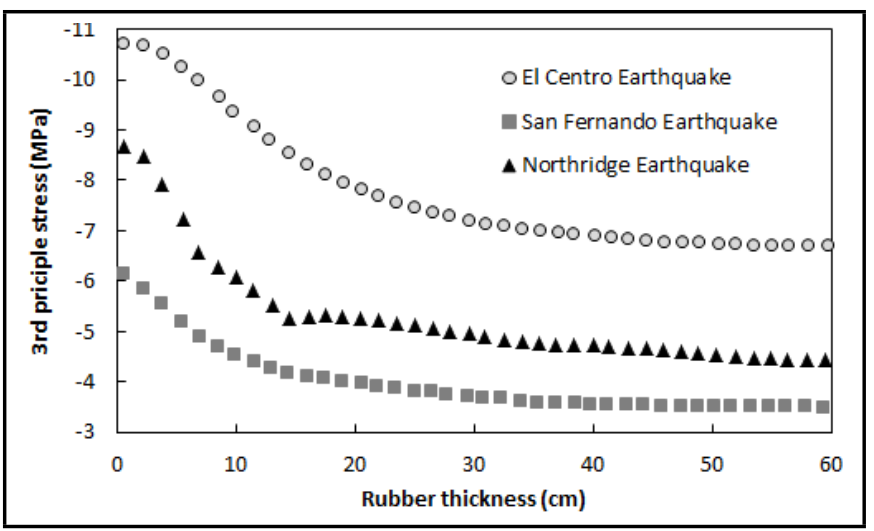

Figure 7. Sensitivity of the $3^{\text {rd }}$ principle stress of the dam toe to the thickness of the rubber damper.

numerical values of results are shown in the Tables 5, 6 and 7 for selected earthquakes. According to the tables, the rubber damper with a thickness in the range of $10 \mathrm{~cm}$ to $15 \mathrm{~cm}$ has the best performance for seismic optimization of the model under the El Centro, the San Fernando and the North Ridge earthquakes, respectively.

\subsection{Optimization of the Rubber Damper Height}

For optimization of the rubber damper thickness using probabilistic analysis and in order to increase the accuracy of the results of the analysis, the sensitivity of the seismic responses of the dam relative to the height of the hydrodynamic damper is extracted from the hydrodynamic damper model. Considering the height of the hydrodynamic damper as a design variable, the results of the probabilistic analysis under the El Centro, San Fernando and Northridge earthquakes are presented in Figs. 8 to 11 .

As shown in Fig. 8, the better performance of the isolation layer in the reduction of hydrodynamic pressure is the rubber damper with the height of $80 \mathrm{~m}, 20 \mathrm{~m}$ and $60 \mathrm{~m}$ under the El Centro, San Fernando and Northridge earthquakes, respectively.

Fig. 9 also shows the effectiveness of the isolation layer height on reducing the horizontal displacement of the dam crest for three modeled earthquakes is similar and the rubber damper with a $100 \mathrm{~m}$ height reduced displacement significantly. Exceeding this amount does not have a considerable effect on reducing the horizontal displacement of the dam crest. 
Table 5. Characteristics of uncertainty parameters of the model for the Monte Carlo probabilistic analysis settings.

\begin{tabular}{|c|c|c|c|c|c|c|c|c|}
\hline \multirow{2}{*}{$\begin{array}{c}\text { Layer } \\
\text { thickness } \\
(\mathrm{cm})\end{array}$} & \multicolumn{3}{|c|}{ S1 } & \multicolumn{2}{|c|}{ S3 } & \multicolumn{2}{c|}{ Press } & \multicolumn{2}{c|}{ Ux } \\
\cline { 2 - 10 } & $\begin{array}{c}\text { Value } \\
(\mathrm{MPa})\end{array}$ & $\begin{array}{c}\text { Reduction } \\
(\%)\end{array}$ & $\begin{array}{c}\text { Value } \\
(\mathrm{MPa})\end{array}$ & $\begin{array}{c}\text { Reduction } \\
(\%)\end{array}$ & $\begin{array}{c}\text { Value } \\
(\mathrm{MPa})\end{array}$ & $\begin{array}{c}\text { Reduction } \\
(\%)\end{array}$ & $\begin{array}{c}\text { Value } \\
(\mathrm{Cm})\end{array}$ & $\begin{array}{c}\text { Reduction } \\
(\%)\end{array}$ \\
\hline 0 & 9.7 & - & 10.7 & - & 0.3411 & - & 4.11 & - \\
\hline 5 & 9.4 & 3.1 & 10.3 & 3.7 & 0.3239 & 5.1 & 4 & 2.7 \\
\hline 10 & 8.4 & 13.4 & 9.35 & 12.6 & 0.3002 & 12 & 3.615 & 12.1 \\
\hline 15 & 7.3 & 24.7 & 8.53 & 20.3 & 0.2675 & 21.6 & 3.275 & 20.3 \\
\hline 20 & 6.7 & 30.9 & 7.81 & 27 & 0.2063 & 39.5 & 3.031 & 26.2 \\
\hline 25 & 6.3 & 35.1 & 7.47 & 30.2 & 0.1801 & 47.2 & 2.885 & 29.8 \\
\hline 30 & 6 & 38.1 & 7.21 & 32.6 & 0.1672 & 51 & 2.774 & 32.5 \\
\hline 60 & 5.3 & 45.4 & 6.69 & 37.5 & 0.1390 & 59.2 & 2.514 & 38.8 \\
\hline
\end{tabular}

Table 6. Results from the probabilistic analysis for the model under San Fernando earthquake.

\begin{tabular}{|c|c|c|c|c|c|c|c|c||}
\hline \multirow{2}{*}{$\begin{array}{c}\text { Layer } \\
\text { thickness } \\
(\mathrm{cm})\end{array}$} & \multicolumn{3}{|c|}{ S1 } & \multicolumn{2}{|c|}{ S3 } & \multicolumn{2}{c|}{ Press } & \multicolumn{2}{c|}{ Ux } \\
\cline { 2 - 9 } & $\begin{array}{c}\text { Value } \\
(\mathrm{MPa})\end{array}$ & $\begin{array}{c}\text { Reduction } \\
(\%)\end{array}$ & $\begin{array}{c}\text { Value } \\
(\mathrm{MPa})\end{array}$ & $\begin{array}{c}\text { Reduction } \\
(\%)\end{array}$ & $\begin{array}{c}\text { Value } \\
(\mathrm{MPa})\end{array}$ & $\begin{array}{c}\text { Reduction } \\
(\%)\end{array}$ & $\begin{array}{c}\text { Value } \\
(\mathrm{Cm})\end{array}$ & $\begin{array}{c}\text { Reduction } \\
(\%)\end{array}$ \\
\hline 0 & 6.7 & - & 6.15 & - & 0.3772 & - & 2.9 & - \\
\hline 5 & 6 & 10.4 & 5.19 & 15.6 & 0.2561 & 32.1 & 2.449 & 15.5 \\
\hline 10 & 5.1 & 23.9 & 4.52 & 26.5 & 0.1736 & 54 & 2.149 & 25.9 \\
\hline 15 & 4.6 & 31.3 & 4.15 & 32.5 & 0.1685 & 55.3 & 1.964 & 32.3 \\
\hline 20 & 4.2 & 37.3 & 3.96 & 35.6 & 0.1610 & 57.3 & 1.864 & 35.7 \\
\hline 25 & 4 & 40.3 & 3.82 & 37.9 & 0.1515 & 59.8 & 1.8 & 37.9 \\
\hline 30 & 3.9 & 41.8 & 3.72 & 39.5 & 0.1429 & 62.1 & 1.735 & 40.2 \\
\hline 60 & 3.6 & 46.7 & 3.49 & 43.2 & 0.1038 & 72.5 & 1.616 & 44.3 \\
\hline
\end{tabular}

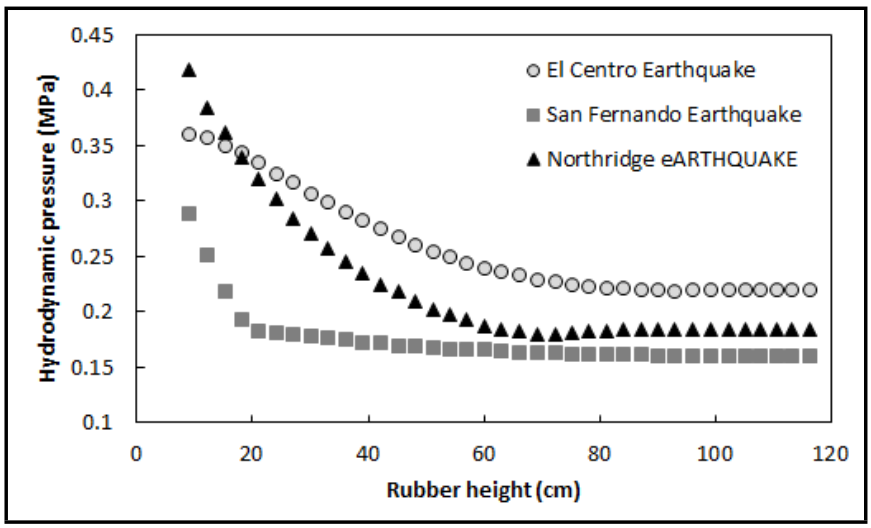

Figure 8. Sensitivity of the hydrodynamic pressure of the dam heel to the height of the rubber damper.

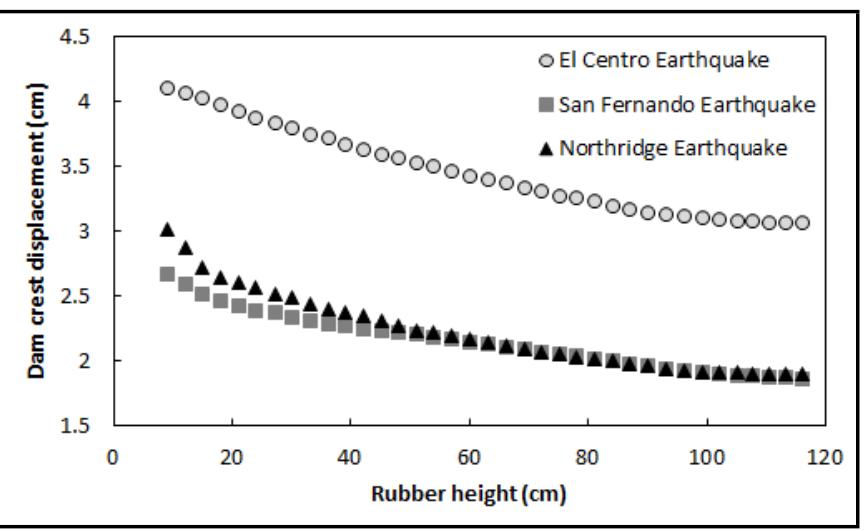

Figure 9. Sensitivity of the horizontal displacement of dam crest to the height of the rubber damper.

According to Fig. 10, the hydrodynamic damper reduces the main tensile stresses applied on the dam up to 90 meters effectively for models under selected earthquakes and exceeding this amount has no significant effect in reducing the main tensile stress on the dam.

Fig. 11 represents that the hydrodynamic damper up to a height of approximately $100 \mathrm{~m}$ can reduce the induced main

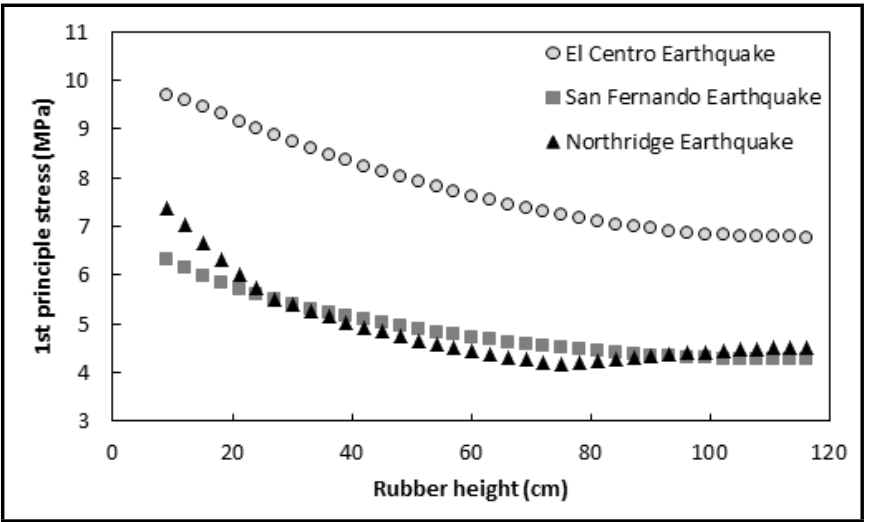

Figure 10. Sensitivity of the $1^{\text {st }}$ principle stress of the dam heel to the height of the rubber damper.

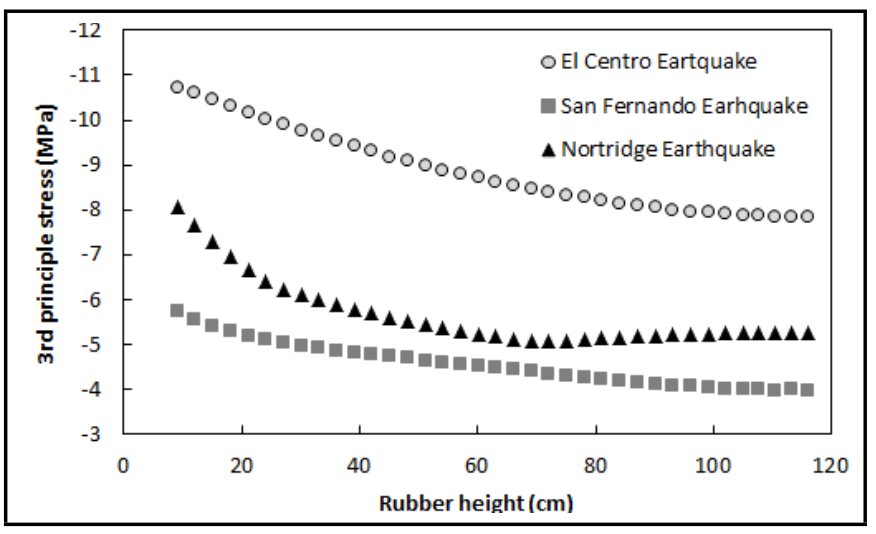

Figure 11. Sensitivity of the $3^{\text {rd }}$ principle stress of the dam heel to the height of the rubber damper.

compressive stress on the dam considerably for the system under the El Centro and Northridge earthquakes. For the San Fernando earthquake, the best performance for the isolation layer is the rubber damper with a $70 \mathrm{~m}$ height.

Finally, for a more appropriate investigation, the effect of a hydrodynamic damper height on reducing the seismic responses of numerical values of responses due to applied earth- 
Table 7. Results of probabilistic analysis for the model under the Northridge earthquake.

\begin{tabular}{|c|c|c|c|c|c|c|c|c|}
\hline \multirow{2}{*}{$\begin{array}{c}\text { Layer } \\
\text { thickness } \\
(\mathrm{cm})\end{array}$} & \multicolumn{3}{|c|}{ S1 } & \multicolumn{2}{|c|}{ S3 } & \multicolumn{2}{c|}{ Press } & \multicolumn{2}{c|}{ Ux } \\
\cline { 2 - 10 } & $\begin{array}{c}\text { Value } \\
(\mathrm{MPa})\end{array}$ & $\begin{array}{c}\text { Reduction } \\
(\%)\end{array}$ & $\begin{array}{c}\text { Value } \\
(\mathrm{MPa})\end{array}$ & $\begin{array}{c}\text { Reduction } \\
(\%)\end{array}$ & $\begin{array}{c}\text { Value } \\
(\mathrm{MPa})\end{array}$ & $\begin{array}{c}\text { Reduction } \\
(\%)\end{array}$ & $\begin{array}{c}\text { Value } \\
(\mathrm{Cm})\end{array}$ & $\begin{array}{c}\text { Reduction } \\
(\%)\end{array}$ \\
\hline 0 & 8 & - & 8.68 & - & 0.51632 & - & 3.25 & - \\
\hline 5 & 7 & 12.5 & 7.3 & 15.9 & 0.33858 & 34.4 & 2.7 & 17 \\
\hline 10 & 5.3 & 33.7 & 6.06 & 30.2 & 0.27598 & 46.5 & 2.4 & 26.2 \\
\hline 15 & 4.5 & 43.7 & 5.1 & 41.2 & 0.20144 & 61 & 2.084 & 35.9 \\
\hline 20 & 4.4 & 45 & 5.3 & 38.9 & 0.1827 & 64.6 & 1.9 & 41.5 \\
\hline 25 & 4.1 & 48.7 & 5.11 & 41.1 & 0.18957 & 63.3 & 1.868 & 42.5 \\
\hline 30 & 3.9 & 51.2 & 4.9 & 43.5 & 0.18307 & 64.5 & 1.883 & 42.1 \\
\hline 60 & 3.6 & 55 & 4.43 & 49 & 0.13278 & 74.3 & 1.704 & 47.6 \\
\hline
\end{tabular}

quakes are presented in Tables 8 to 10 . According to these tables, choosing the height of a hydrodynamic damper in the range of $80 \mathrm{~m}$ to $90 \mathrm{~m}$, leads to an optimal use of the hydrodynamic damper with a safe and economic design of the case model of the concrete gravity dam.

\section{CONCLUSION}

In this paper, to control the interaction effects and dissipation of induced hydrodynamic pressure, the formulation is used in a study of the effects of the rubber damper as an isolation layer on the seismic optimization of the dam model. In particular, the computational treatment of the damreservoir-foundation region with an upstream rubber damper by the software and finite element model is described in detail. To assess the optimum thickness and height of the rubber damper, the Monte Carlo simulation and sensitivity analysis are applied.

The obtained results show that, the isolation layer reduces the displacement and stresses of the dam because the absorptive and flexible isolation layer has a damping effect on induced hydrodynamic pressure during earthquake. Also, the thickness and height of the isolation layer have a different effect on the reduction of seismic responses which reduce the amplitude of the hydrodynamic pressure at the dam-reservoir interface.

The comparison of the proper function of the Monte Carlo probability analysis versus the assessment of the rubber damper thickness and height on the seismic behavior shows that the Monte Carlo method is a useful tool for the optimization and safe design by understanding the effects of various parameters on the seismic performance.

Using the results of probabilistic analysis of the model which represents the sensitivity of seismic reaction of the dam to the rubber damper thickness and height, the suitable range of the rubber damper thickness and height for optimum design is presented. Based on the obtained results and considering costs and economic points, it can be concluded that the rubber damper with a thickness of 10 to $20 \mathrm{~cm}$ and height of 80 to $90 \mathrm{~m}$ has the best performance on reducing seismic responses of the dam. The optimal selection of the isolation layer height and thickness depend on its effectiveness in reduction of response considering economic and executive justification.

Finally, it can be concluded that the presented model is applicable in the safe design of concrete dams and even existing dams due to the scarcity of water resources and the enormous costs of building dams. The concept of a safe structure refers to the structures that continue to function without damage and failure for many years.

\section{REFERENCES}

1 Chopra, A. K. Hydrodynamic pressures on dams during earthquakes, Journal of Engineering Mechanics Division, 93(6), 205-224, (1967). https://dx.doi.org/10.1017/S0022112086003026

2 Hanna, Y. G. and Humar, J. L. Boundary element analysis of fluid domain, Journal of Engineering Mechanics Division, 108(2), 436-450, (1982).

3 Tsai, C. S. and Lee, G. C. Hydrodynamic pressure on gravity dams subjected to ground motions, Journal of Engineering Mechanics, 115(3), 598617, (1989). https://dx.doi.org/10.1061/(asce)07339399(1989)115:3(598)

${ }^{4}$ Hatami, K. Effect of reservoir boundaries on the seismic response of gravity dams, Doctoral dissertation, McMaster University, (1997).

5 Bayraktar, A., Türker, T., Akköse, M. and Ateş, Ş. The effect of reservoir length on seismic performance of gravity dams to near- and far-fault ground motions, Natural Hazards, 52(2), 257-275, (2010). https://dx.doi.org/10.1007/s11069-009-9368-1

6 Wang, G., Zhang, S., Wang, C. and Yu, M. Seismic performance evaluation of dam-reservoir-foundation systems to near-fault ground motions, Natural Hazards, 72(2), 651674, (2014). https://dx.doi.org/10.1007/s11069-013-1028-9

7 Lombardo, V. N., Mikhailov, L. P. and Semenov, I.V. Studies and design of earthquake resistant concrete dams, Proceedings of international symposium on earthquake and dams, ICOLD, Beijing, China, 1, 233-241, (1987).

8 Sheinin, I. S. An air curtain for Protecting Hydraulic Structures from seismic and blast effects, $H y$ drotechnical Construction, 26(10), 609-615, (1992). https://dx.doi.org/10.1007/bf01544762

9 Savinov, O. A., Sheinin, I. S., Kalitseva, I. S. and Sheinina, S.I. Mathematical modeling and theoretical studies of problems of seismic stability of hydraulic structures with an air curtain, Hydrotechnical Construction, 26(10), 631-635, (1992). https://dx.doi.org/10.1007/bf01544767

10 As'kov, V. L., Kalitseva, I. S., Komarov, A.I. and Sheinin, I. S. Physical modeling of phenomena of the interaction 
Table 8. Results of probabilistic analysis for the model under El Centro earthquake.

\begin{tabular}{||c|c|c|c|c|c|c|c|c||}
\hline \multirow{2}{*}{$\begin{array}{c}\text { Layer } \\
\text { Height } \\
(\mathrm{m})\end{array}$} & \multicolumn{2}{|c|}{ S1 } & \multicolumn{2}{|c|}{ S3 } & \multicolumn{2}{c|}{ Press } & \multicolumn{2}{c|}{ Ux } \\
\cline { 2 - 10 } & $\begin{array}{c}\text { Value } \\
(\mathrm{MPa})\end{array}$ & $\begin{array}{c}\text { Reduction } \\
(\%)\end{array}$ & $\begin{array}{c}\text { Value } \\
(\mathrm{MPa})\end{array}$ & $\begin{array}{c}\text { Reduction } \\
(\%)\end{array}$ & $\begin{array}{c}\text { Value } \\
(\mathrm{MPa})\end{array}$ & $\begin{array}{c}\text { Reduction } \\
(\%)\end{array}$ & $\begin{array}{c}\text { Value } \\
(\mathrm{Cm})\end{array}$ & $\begin{array}{c}\text { Reduction } \\
(\%)\end{array}$ \\
\hline 0 & 9.7 & - & 10.7 & - & 0.341 & - & 4.11 & - \\
\hline 9.1 & 9.69 & 0.028 & 10.71 & -0.1214 & 0.360 & -5.712 & 4.09 & 0.29 \\
\hline 20 & 9.169 & 5.47 & 10.17 & 4.93 & 0.33 & 1.61 & 3.92 & 4.52 \\
\hline 40 & 8.35 & 13.85 & 9.41 & 12.02 & 0.282 & 17.15 & 3.67 & 10.66 \\
\hline 60 & 7.62 & 21.37 & 8.71 & 18.58 & 0.24 & 29.61 & 3.42 & 16.59 \\
\hline 70 & 7.38 & 23.86 & 8.46 & 20.85 & 0.23 & 32.66 & 3.33 & 18.76 \\
\hline 80 & 7.11 & 26.61 & 8.20 & 23.34 & 0.223 & 34.78 & 3.22 & 21.50 \\
\hline 90 & 6.95 & 28.26 & 8.048 & 24.78 & 0.22 & 35.44 & 3.15 & 23.28 \\
\hline 100 & 6.84 & 29.41 & 7.93 & 25.83 & 0.22 & 35.21 & 3.09 & 24.57 \\
\hline 110 & 6.78 & 30.042 & 7.853 & 26.59 & 0.22 & 35.216 & 3.06 & 25.32 \\
\hline 116 & 6.77 & 30.17 & 7.85 & 26.63 & 0.22 & 35.21 & 3.06 & 25.31 \\
\hline
\end{tabular}

Table 9. Results of probabilistic analysis for the model under San Fernando earthquake.

\begin{tabular}{|c|c|c|c|c|c|c|c|c|}
\hline $\begin{array}{c}\text { Layer } \\
\text { Height } \\
(\mathrm{m})\end{array}$ & \multicolumn{3}{|c|}{ S1 } & \multicolumn{2}{|c|}{ S3 } & \multicolumn{2}{|c|}{ Press } & \multicolumn{2}{c|}{ Ux } \\
\cline { 2 - 10 } & $\begin{array}{c}\text { Value } \\
(\mathrm{MPa})\end{array}$ & $\begin{array}{c}\text { Reduction } \\
(\%)\end{array}$ & $\begin{array}{c}\text { Value } \\
(\mathrm{MPa})\end{array}$ & $\begin{array}{c}\text { Reduction } \\
(\%)\end{array}$ & $\begin{array}{c}\text { Value } \\
(\mathrm{MPa})\end{array}$ & $\begin{array}{c}\text { Reduction } \\
(\%)\end{array}$ & $\begin{array}{c}\text { Value } \\
(\mathrm{Cm})\end{array}$ & $\begin{array}{c}\text { Reduction } \\
(\%)\end{array}$ \\
\hline 0 & 6.7 & - & 6.15 & - & 0.377 & - & 2.9 & - \\
\hline 9.1 & 6.337 & 5.4 & 5.74 & 6.67 & 0.288 & 23.42 & 2.66 & 8.02 \\
\hline 20 & 5.713 & 14.717 & 5.186 & 15.67 & 0.182 & 51.726 & 2.43 & 16.27 \\
\hline 40 & 5.165 & 22.91 & 4.816 & 21.7 & 0.173 & 54.1 & 2.27 & 21.65 \\
\hline 60 & 4.72 & 29.47 & 4.516 & 26.6 & 0.165 & 56.2 & 2.15 & 25.9 \\
\hline 70 & 4.58 & 31.56 & 4.38 & 28.65 & 0.163 & 56.84 & 2.1 & 27.71 \\
\hline 80 & 4.43 & 33.79 & 4.22 & 31.32 & 0.161 & 57.26 & 2.01 & 30.44 \\
\hline 90 & 4.35 & 34.97 & 4.12 & 33 & 0.16 & 57.36 & 1.96 & 32.25 \\
\hline 100 & 4.29 & 35.84 & 4.04 & 34.34 & 0.160 & 57.46 & 1.91 & 33.99 \\
\hline 110 & 4.27 & 36.22 & 3.97 & 35.30 & 0.160 & 57.45 & 1.87 & 35.31 \\
\hline 116 & 4.2611 & 36.40 & 3.969 & 35.45 & 0.160 & 57.54 & 1.86 & 35.72 \\
\hline
\end{tabular}

of hydraulic structures with water in the presence of an air curtain, Hydrotechnical Construction, 26(10), 636-646, (1992). https://dx.doi.org/10.1007/bf01544768

11 Gellis, V. K., Kalitseva, I. S., Mel'nikov, E.P. and Sheinin, I. S. On-site studies of an experimental air curtain on the dam of the Krivoporozhsk hydroelectric station, Hydrotechnical Construction, 26(10), 647-652, (1992). https://dx.doi.org/10.1007/bf01544769

12 Zhang, S. J., Chen, J., Zhang, Y. Z. and Liu, H.W. Research of air-cushion isolation effects on high arch dam reservoir, Acta Mechanica Sinica, 27(5), 675-686, (2011). https://dx.doi.org/10.1007/s10409-011-0481-5

13 Mirzabozorg, H., Lamea, M. and Sehat, H. Hydrodynamic isolation and 3D seismic response of concrete arch dams, Dam Engineering International Journal, 22(3), 227-250, (2012).

14 Chen, J., Xiong, F. and Ge, Q. Study on air-cushion isolation control of concrete dam and its anti-cracking effect, Journal of Vibroengineering, 20(4), 1761-1773, (2018). https://dx.doi.org/10.21595/jve.2017.18739

15 Hall, J. F. and El-Aidi, B. Hydrodynamic isolation of concrete dams, Seismic engineering at structure congress, San Francisco, 307-316, (1989).

16 Hall, J. F., Dowling, M. J. and El-Aidi, B. Defensive design of concrete gravity dams, Dam Engineering, 3(4), 249-263, (1992).
17 Fairbairn, E. M., Silvoso, M. M., Toledo Filho, R.D., Alves, J.L. and Ebecken, N.F. Optimization of mass concrete construction using genetic algorithms, Computers and structures, 82(2), 281-299, (2004). https://dx.doi.org/10.1016/j.compstruc.2003.08.008

18 Kostov, M., Boncheva, H., Stefanov, D., Varbanov, G., Kaneva, A. aand Koleva, N. Seismic risk assessment of large concrete gravity dams, In 11th European Conference on Earthquake Engineering, Paris, (1998).

19 Yanmaz, A. M. and Beşer, M. R. On the Reliability-Based Safety Analysis of the Porsuk Dam, Turkish Journal of Engineering and Environmental Sciences, 29(5), 309-320, (2005).

20 Rohaninejad, M. and Zarghami, M. Combining Monte Carlo and finite difference methods for effective simulation of dam behavior, Advances in Engineering Software, 45(1), 197-202, (2012). https://dx.doi.org/10.1016/j.advengsoft.2011.09.023

21 Lupoi, A. and Callari, C. A probabilistic method for the seismic assessment of existing concrete gravity dams, Structure and Infrastructure Engineering, 8(10), 985-998, (2012). https://dx.doi.org/10.1080/15732479.2011.574819

22 Altarejos-García, L., Escuder-Bueno, I. and SerranoLombillo, A. and de Membrillera-Ortuño, M.G. Methodology for estimating the probability of failure by sliding in concrete gravity dams in the context of risk analysis, Structural safety, 36, 1-13, (2012). https://dx.doi.org/10.1016/j.strusafe.2012.01.001 
Table 10. Results of probabilistic analysis for the model under North Ridge earthquake.

\begin{tabular}{||c|c|c|c|c|c|c|c|c||}
\hline \multirow{2}{*}{$\begin{array}{c}\text { Layer } \\
\text { Height } \\
(\mathrm{m})\end{array}$} & \multicolumn{2}{|c|}{ S1 } & \multicolumn{2}{|c|}{ S3 } & \multicolumn{2}{c|}{ Press } & \multicolumn{2}{c|}{ Ux } \\
\cline { 2 - 10 } & $\begin{array}{c}\text { Value } \\
(\mathrm{MPa})\end{array}$ & $\begin{array}{c}\text { Reduction } \\
(\%)\end{array}$ & $\begin{array}{c}\text { Value } \\
(\mathrm{MPa})\end{array}$ & $\begin{array}{c}\text { Reduction } \\
(\%)\end{array}$ & $\begin{array}{c}\text { Value } \\
(\mathrm{MPa})\end{array}$ & $\begin{array}{c}\text { Reduction } \\
(\%)\end{array}$ & $\begin{array}{c}\text { Value } \\
(\mathrm{Cm})\end{array}$ & $\begin{array}{c}\text { Reduction } \\
(\%)\end{array}$ \\
\hline 0 & 8 & - & 8.68 & - & 0.516 & - & 3.25 & - \\
\hline 9.1 & 7.4 & 7.6 & 8.07 & 7.03 & 0.418 & 19 & 3.02 & 7 \\
\hline 20 & 6.01 & 24.9 & 6.65 & 23.33 & 0.32 & 38 & 2.6 & 19.9 \\
\hline 40 & 5.04 & 37 & 5.78 & 33.38 & 0.23 & 54.6 & 2.37 & 26.9 \\
\hline 60 & 4.44 & 44.5 & 5.22 & 39.8 & 0.187 & 63.6 & 2.17 & 33.3 \\
\hline 70 & 4.26 & 46.7 & 5.06 & 41.7 & 0.18 & 65.2 & 2.1 & 35.4 \\
\hline 80 & 4.24 & 47 & 5.13 & 40.9 & 0.18 & 64.6 & 2.01 & 38 \\
\hline 90 & 4.34 & 45.7 & 5.2 & 40.2 & 0.18 & 64.3 & 2 & 39.5 \\
\hline 100 & 4.42 & 44.7 & 5.22 & 39.8 & 0.185 & 64.2 & 1.9 & 40.8 \\
\hline 110 & 4.49 & 43.7 & 5.26 & 39.3 & 0.184 & 64.1 & 1.90 & 41.5 \\
\hline 116 & 4.50 & 43.65 & 5.26 & 39.29 & 0.184 & 64.17 & 1.89 & 41.6 \\
\hline
\end{tabular}

23 Feng, G., Ma, C., Zheng, D. J., Yao, Z., You, L. F. and Tang, D. Z. The Application of MATLAB-Based Monte Carlo Method in Hydraulic Structures Reliability, In Applied Mechanics and Materials, 351, 1576-1580, (2013). https://dx.doi.org/10.4028/www.scientific.net/amm.351352.1576

24 Mirzabozorg, H., Akbari, M. and Hariri-Ardebili, M. A. Nonlinear seismic response of a concrete arch dam to spatially varying earthquake ground motions, Asian Journal of Civil Engineering (BHRC), 14(6), 859-879, (2013).

25 Alembagheri, M. and Seyedkazemi, M. Seismic performance sensitivity and uncertainty analysis of gravity dams, Earthquake Engineering and Structural Dynamics, 44(1), 41-58, (2015). https://dx.doi.org/10.1002/eqe.2457

26 Pasbani Khiavi, M. Investigation of the effect of reservoir bottom absorption on seismic performance of concrete gravity dams using sensitivity analysis, KSCE Journal of Civil Engineering, 20(5), 1977-1986, (2016). https://dx.doi.org/10.1007/s12205-015-1159-5

27 Chiti, H., Khatibinia, M., Akbarpour, A. and Naseri, H. R. Reliability-based design optimization of concrete gravity dams using subset simulation, International Journal of Optimization in Civil Engineering, 6(3), 329-348, (2016).

28 Pasbani Khiavi, M. Investigation of seismic performance of concrete gravity dams using probabilistic analysis, Journal of Croatian Association of Civil Engineers, 69(1), 21-29, (2017). https://dx.doi.org/10.14256/jce.1454.2015

29 Sevieri, G., Andreini, M., De Falco, A. and Matthies, H. G. Concrete gravity dams model parameters updating using static measurements, Engineering Structures, 196, (2019). https://dx.doi.org/10.1016/j.engstruct.2019.05.072
30 Dong, L., Sun, D., Li, X., Ma, J., Zhang, L. and Tong, X. Interval non-probabilistic reliability of surrounding jointed rockmass considering microseismic loads in mining tunnels, Tunnelling and Underground Space Technology, 81, 326-335, (2018). https://dx.doi.org/10.1016/j.tust.2018.06.034

31 Bae, H. R., Grandhi, R. V. and Canfield, R. A. Epistemic uncertainty quantification techniques including evidence theory for large-scale structures, Computers and Structures, 82(13-14), 1101-1112, (2004). https://dx.doi.org/10.1016/j.compstruc.2004.03.014

32 Rubinstein, R.Y. and Kroese, D. P. Simulation and the Monte Carlo method, John Wiley and Sons. Inc. Publication, (1981). https://dx.doi.org/10.1002/9780470316511

33 Matos, J. Uncertainty treatment in civil engineering numerical models, M. Sc. Thesis, University of Porto, (2007).

${ }^{34}$ Løkke, A. and Chopra, A. K. Response Spectrum Analysis of Concrete Gravity Dams Including Dam-WaterFoundation Interaction, Journal of structural engineering, 141(8), (2015). https://dx.doi.org/10.1061/(asce)st.1943$541 \times .0001172$

35 Fenves, G. and Chopra, A. K. Effects of reservoir bottom absorption and dam-water-foundation rock interaction on frequency response functions for concrete gravity dams, Earthquake engineering and structural dynamics, 13(1), 13-31, (1985). https://dx.doi.org/10.1016/01489062(85)92284-3

36 ANSYS user Manual Release 11.0 for Documentation of ANSYS, SAS IP, Inc., (2007).

37 Bathe, K. J. Finite element procedures, Prentice Hall, Upper Saddle River, Newjersy: 07458, (1996). 